\title{
LA VILLA ARAGONESA DE ÉPILA EN EL SIGLO XV: SUS JUDÍOS *
}

ENCARNACIÓN MARÍN PADILLA

CSIC Madrid

\section{JUDERÍA}

Como he señalado con anterioridad, en Épila no existió judería propiamente dicha, no hubo un lugar en la villa donde sus moradores fueran sólo judíos. Los componentes de la comunidad hebrea tuvieron sus casas en torno a las puertas y en los barrios donde vivieron los cristianos y los pocos moros que allí residieron.

La forzosa convivencia en la villa de seguidores de distintas leyes religiosas a causa de la falta de un barrio judío o judería, motivó que cuando en el segundo año del siglo XV, concretamente el 16 de abril de 1401, el concejo cristiano -infanzones, clérigos y labradores- se reunió en la plaza, avisado por el corredor según costumbre, para hacer "estatuto et paramiento" de que, a partir de ese momento, se guardara y acatara el día "santo del domingo por servicio de nuestro senyor Dios", desde el sábado «el sol puesto en adevant» ${ }^{318}$, se ordenara a los judíos que no "fagan ni facer puedan facenderia alguna el dito dia ha puerta abierta" o incurrirían en multa como los cristianos ${ }^{319}$.

\footnotetext{
* Continuación de Sef LIII (1993) 59-102 y 289-320; LIV (1994) 55-82 y 307-332.

318 De manera que ningún vecino ni residente en la villa "no faga ni facer faga ... facenderia alguna, es a saber: cavar, podar, arar, regar, abentar ni faxinar pan ni enbasar para Çaragoça a levar pan, ni segar sino solament alcazer et hierba para las bestias suyas propias de cada uno et non para vender". Quien infringiera dicho estatuto sería penado, cada vez, con "huna livra de cera" para la iglesia mayor de la villa; dicha pena sería "acusada et levada" por el vicario de dicha iglesia y por los mayordomos de la cofradía de las Virtudes.

319 El objeto del estatuto, que sería "por todos tiempos firme et valedero", era que "por sienple" fuera observado el domingo. El concejo se comprometió, además y obligó todos sus bienes a cumplirlo, a "no venir ni facer venir cuentra aquel en algun tiempo ni por alguna raçon»; y para que el domingo se respetara, nombró a los dos mayordomos de dicha cofradía, que deberían jurar y "fagan sagrament" al igual que
} 
Aunque luego me referiré más extensamente a las puertas y barrios de la villa donde ocuparon casas los judíos, conviene señalar que las preferencias de las familias hebreas se inclinaron por las puertas de la Acequia y de las Eras -en la de la Peña sólo tuvieron corrales, huertos y tañerías-, y por los barrios del Burgo, las Herrerías y la Plaza; en los barrios del Castillo y de Santa María no vivieron judíos; en el del Azanet sólo tuvieron tañerías y huertos; y en el del Purniello únicamente residió un miembro de la familia Gallur, cuyo nombre no consta, en 1420 , y en 1451 el «cilurgico» maestre Ezmel Abenabez tuvo una casa a loguero del escudero de Tarazona Ximeno García de Villanueva, con un mirador; algunas casas de cristianos, sitas en este barrio, lindaban con corrales de casas de judíos.

\section{SiNAGOGA}

En mi anterior artículo sobre la villa de Épila en el siglo XIV, hacía referencia a las casas del escudero Gonzalvo de Arbués, sitas en el barrio de las Herrerías y contiguas a la «sinoga biella que solia seer", que lindaba con el muro de la villa. Esta denominación ponía de manifiesto la existencia de otra sinagoga a finales de dicho siglo y que la vieja había dejado de tener uso como tal y es posible que hubiera pasado a ser propiedad particular según un documento fechado en $1397{ }^{320}$.

La nueva sinagoga se encontraba cerca de la vieja, pues a ella se "puyava" por una carrera del citado barrio de las Herrerías ${ }^{321}$, pero también se podía acceder a la misma por un callizo que partía del barrio de la Plaza ${ }^{322}$. La ubicación de esta sinagoga dio nombre a un barrio de la villa ${ }^{323}$, el de la Sinagoga - con una

sus sucesores al tomar posesión de sus cargos, de que junto con el vicario acusarían e impondrían dicha pena a quienes quebrantaran el domingo y fueran contra lo ordenado (L.A.APN., Remiro de Sádaba, 1401, fols. 52-54).

320 "La villa de Épila», 330 y 338.

${ }^{321}$ En 1414 el judío zaragozano Juce Alazar dio a loguero a Acach Azarias unas casas, con bodega y "baxiellos", en el barrio de las Herrerías, en el callizo "que puya a la sinogan; lindaban con las de rabí Saya y con las de Simuel Baylo (dicho notario, 1414, fols. 44-44v).

322 L.A.APN., Martín de Talamanca, 1405, fols. 48v-49.

${ }^{323}$ Aunque en la documentación aparece la denominación "barrio de la sinoga», dudo se tratara realmente de un barrio por el pequeño espacio que comprendía. 
carrera pública y dos callizos-, donde vivieron cristianos y judíos ${ }^{324}$.

No me consta cuándo empezó a usarse esta sinagoga, cuya edificación no parece de nueva planta a tenor de las noticias documentales que a ella se refieren. Desde el año 1421 el importe de algunos legados testamentarios estaba destinado a su "hadobo e reparacion" ${ }^{325}$ y cuatro años después, en 1425, continuaban las restauraciones en la sinagoga ${ }^{326}$. Antes de transcurrir la segunda mitad del siglo XV, se necesitó hacer en el edificio nuevas obras y rabí Abraham Albo, como adelantado, y la propia aljama acordaron determinados capítulos con el moro zaragozano maestre Ibrahim de Romi, "maestro de obras de casas", para llevarlas a cabo a destajo. El incumplimiento de lo pactado por parte de la aljama, según parece, motivó que maestre Ibrahim, que por entonces se encontraba en Urrea, se personara en la villa de Épila el viernes 13 de febrero de 1445. Allí, en las casas de Martín de Suñén, en presencia del

${ }^{324}$ En 1405 las casas del racionero Pedro de Azafar, sitas «ius la plaça», lindaban con "caliço que salle a la sinoga de los jodios e con la dita sinoga" (dicho notario, año y folios). En 1421 las casas del escudero Ximeno de Rueda que dio a loguero a Hahim Leredi, estaban sitas "en el callizo de la sinoga" (L.A.APN., Remiro de Sádaba, 1421, fol. 74). En 1474 las casas de Miguel de Sicilia lindaban con la "sinoga" de los judíos, con las de Abraham Sumiel y con carrera pública (Z.APN., Antón de Abiego, 1474, fol. 33). Desde 1461 hasta 1491 la sinagoga lindaba con las casas de labrador Juan de Sarriá o Sánchez de Sarriá por uno de sus lados; en este último año las casas de Juan lindaban, además, con las del judío Mosse Sumiel, con carrera pública y con las de Pedro de Medina (L.A.APN., Martín Ramo, 1491, fols. 88v-89). También en 1491 "la sinoga de los judios" lindaba con casas del presbítero García de Soria que, a su vez, lo hacían con las del escudero Gonzalvo de Arbués, con las de Jamila Gadax y con carrera pública (Z.APN., Antón de Abiego, 1494, fol. 61; donde se recoge el documento).

${ }^{325} \mathrm{La}$ judía Horbellido ordenó en su testamento que lo que le debían algunos judíos de la villa, en total: cinco florines y medio, medio cahíz de candeal, dos fanegas de trigo y cuarenta y ocho sueldos y medio, se entregara a rabí Saya para que lo empleara en ello. Para evitar repeticiones inútiles las referencias documentales de los testamentos, que serán ampliamente estudiados en el apartado de familias, no aparecerán en este apartado. También la iglesia de la villa necesitó reparaciones: el domingo 3 de abril de 1402, el vicario de la iglesia de la villa, Jaime Lobera, recibió del procurador del concejo Domingo del Tuo doscientos sueldos "para ciertas nezesidades e adobo que ys de nezesidat para la dita eglesia"; otorgó el correspondiente albarán (L.A.APN., Remiro de Sádaba, 1402, fols. 40-40v).

${ }^{326}$ Cuando Abraham Caçon y su hijo Caçon Abencaçon firmaron los capítulos y condiciones del matrimonio de su hija y hermana Jamila con Vidal Amiello, se acordó que, en caso de que alguna de las partes los incumpliera, incurriría en multa de cincuenta florines que se dividirían en tres partes iguales: para la señoría, para la parte cumplidora y para "la obra de la sinoga». Sirva lo dicho en la nota anterior sobre las referencias documentales. 
notario cristiano y testigos «e asaz pro personas entre christianos e judios", hizo el siguiente requerimiento al adelantado:

— "Don Rabi, ya sabez como yo pres de la aljama de aquesta villa a obrar scierta obra a estallo en la sinoga ..., de lo que so tenido fazer en aquella e de lo que vosotros soys tenidos a mí consta e parece por capitoles judaycos fechos entre vosotros e mi que quiere que sian, por tanto que algunas cosas fallecer encara a obrar en aquella viengo deliberado no partir de aquesta villa ... en tanto aquella sia acabada a fazer por mi, requiriendovos a bos, asi como adelantado que vos soys ..., que vos me fagaredes dar toda aquella manobra que a mi faze a menester pora fazer, como yo so presto e parellado fazer aquella. En otra manera vos no dandome lo que a mi ys necesario, por falta de aquello yo he a bagar algunos jornales, que aquellos sian a culpa vuestra e de la aljama e no mia».

A continuación, "protestó de quales misiones" que la interrupción de la obra pudieran ocasionar, pidió que fueran «atribuydas a vos como adelantado e no a mi", y requirió al notario para que levantara acta que mostraría, en caso necesario, en el futuro. Oído el requerimiento, rabí Abraham sin consentir en las protestas manifestadas contra él y la aljama, pidió al notario que no cerrase el acta sin haber él respondido ${ }^{327}$. El desacuerdo entre ambas partes debió de mantenerse más de un año, porque hasta el 6 de marzo de 1446, maestre Ibrahim no se consideró pagado y entregó albarán a la aljama de haber recibido

"todas e qualesquiere quantias de dineros, si quiere florines que la sobre dita aljama a mi fuese tenida dar por razon de todas e qualesquiere obras que yo aya fecho por ellos en la sinoga, si quiere tova de la dita sinoga, en las quales quantidades que de vos dita aljama yo de present me a cargo seyer contento della, me heraredes obligados por contratos de notario publico, si quiere por scripturas privadas" ${ }^{328}$.

327 L.A.APN., Martín de Marín, 1445, fols. 10-10v.

${ }^{328}$ Dicho notario, 1446, fol. 22v. Tal vez para evitar complicaciones como en el caso de Épila, cuando años después se encargó la teba de la sinagoga de la villa de Alagón -en sus acuerdos intervino el judío epilense y "cilurgico" maestre Ezmel Abenabez - al fustero Ali Cambriel, moro de Plasencia del Jalón «e de la partida del senyor justicia de Aragon», se le obligó a reconocer por instrumento público notarial la fecha de entrega y colocación de dicha $t e b a$, quién proporcionaría el material necesario para hacerla y quién pagaría las «misiones». El 21 de mayo de 1454, Ali 
Los acuerdos para hacer las obras que la sinagoga fue necesitando los redactaría el notario judío a petición de la aljama, una vez que los adelantados y ésta llegaban a pactos y capítulos sobre precios, materiales y plazos de entrega con las personas encargadas de realizarlas; de ahí que sólo se tenga constancia de tales obras cuando, por diferentes motivos, una de las partes prefirió comparecer ante un notario cristiano para otorgar un instrumento público con objeto de poder presentarlo, en el futuro, en caso de posibles demandas ante tribunales cristianos. Otras veces la aljama se vio en la necesidad de hacer reparaciones en la sinagoga después de que se le hiciera un requerimiento notarial, motivado por el perjuicio que el estado de la misma ocasionaba a terceros, como ocurrió en 1461 cuando la sinagoga lindaba con el corral del merino Juan Sánchez de Sarriá y el

"agua que scorria del terrado de la sinoga ... cahia en su casa, si quiere corral, indevidament e en grant perjudicio suyo, por lo qual venia grant danyo a su cassa».

El 8 de julio de dicho año, después de exponer el caso ante los adelantados Saya Sumiel y Salamon Levi, el merino los requirió para que

\footnotetext{
reconoció "seyer en verdat yo haver preso a estallo a fazer de manos e de fusta a mi propia mision, de la aljama de los jodios de la villa de Alagon e del honorable maestre Ezmel ... una teba de fusta pora la sinoga de la dita villa ..., por precio feyto entre mi e la sobre dita aljama e el sobre dito maestre ... que me dio por fazer aquella, de trezientos e quaranta solidos e que aquella e la fusta toda de aquella yo he de dar acabada de fazer e seyer asentada en la dita sinoga daquia por todo el mes de setiembre primero venient ..., segunt que de todo, los pactos e condiciones feytos e concordados entre la dita aljama e de mi mas largament se demuestra por capitoles feytos e firmados entre la dita aljama. Et por tal que mi voluntat ys bien de fazer la dita teba, bien e complidament, pora la sobre dita jornada e dar aquella asentada en la dita sinoga segunt star deve, e la dita aljama no tiene seguridat ninguna de mi, por tanto que la dita aljama no quede ni decebida de mi, agora pora la hora prometo e me obligo de fazer la dita teba e aquella dar acabada como dito ys daquia el sobre dito mes de setiembre inclusive primero venient. Et si yo no dare aquella acabada segunt por mi ys proferido fazer aquella. Et por firme a tener e complir todo lo sobre dito, misiones algunas a la dita aljama ni a vos dito maestre vos convendran fazer et a qualquiere manera aquellos prometo pagar, etc., a lo qual obligo mi persona e bienes e renuncio a mi judge, etc.". A continuación, Ali otorgó haber recibido ciento veintiséis sueldos seis dineros de los trescientos cuarenta que los judíos y la aljama de Alagón tenía que entregarle por hacer la teba, a través de dicho maestre Ezmel, y otorgó albarán (dicho notario, 1454, fol. 53).
} 
"providiesen e muit bien, e do no lo fiziesen, lo que no crehia, que protestava contra ellos e qualquiere dellos, en nombre e voz de la dita aljama, de qualesquiere danyos e menoscabos que por causa de la dita agua el pudiese recebir»;

luego pidió al notario que levantara acta de su requerimiento, "en su tiempo e lugar demostradera». La respuesta de los adelantados fue que, si

"danyo ninguno el recibia de la dita agua, ellos en nombre e voz de la dita aljama, eran muit prestos a dar higne remedio, dandoles tiempo competent a poder fazer aquello" ${ }^{329}$;

la contestación a tal requerimiento, dado de quien provenía, no podía ser otra. Ya iniciado el último tercio del siglo XV la sinagoga necesitaba nuevas reparaciones y obras, de las cuales se habían hecho cargo el judío Acach Abenforna y el fustero moro Ali Burueta. El 28 de enero de 1479, en la villa, el escudero zaragozano García de Acín recibió de los adelantados y aljama de Épila «toda aquella quantidat de dineros et CCXXX sueldos por aquellos peones que por casas ... haviays de dar e pagar" a los dichos Acach y Ali, "por razon de las obras que ... devian fazer en la sinoga" ambos ${ }^{330}$.

No me consta si el edificio que albergó a la sinagoga estuvo configurado desde un principio en dos partes o si se dividió así en las sucesivas obras que en él se hicieron, pero a partir de la segunda mitad del siglo XV la sinagoga tuvo dos partes claramente diferenciadas, la que ocupaban las mujeres y la que ocupaban los hombres, que en la documentación aparecen con los nombres de "sinoga de las mulleres" y "sinoga de los hombres", respectivamente, pues no creo probable que se tratara de dos edificios distintos. La entrada a la sinagoga se hacía por dos puertas, situadas una, a mano derecha y otra, a mano izquierda, y la parte dedicada a las mujeres o "sinoga de las mulleres" - que parece estaba «en la çaga»- tenía varios arcos, junto a los cuales se encontraban los asientos o lugares que ellas ocupaban ${ }^{331}$.

${ }^{329}$ Dicho notario, 1461 , fol. $41 \mathrm{v}$.

330 Otorgó el correspondiente albarán (Z.APN., Antón de Abiego, 1479, fol. 63).

${ }^{331}$ La judía Cinha Baylo dejó en su testamento a Sento Amiello un sitio o lugar, situado «al arco primero de la sinoga de las mulleres, a la mano dreita, al rincon del arco». 
Estos asientos o lugares que se asignarían a los judíos cuando el edificio empezó a usarse como sinagoga, y por los que, salvo excepciones, parece que sus dueños tuvieron que pagar una determinada cantidad a la aljama ${ }^{332}$, fueron cambiando de propietario a través de contratos de compra-venta, donaciones o legados testamentarios ${ }^{333}$. Los asientos de la sinagoga tenían distinto valor y diferente precio, según el material y el modo en que estuvieran hechos, y su localización. En la parte reservada a las mujeres o "sinoga de las mulleres" se pagaron veinticinco sueldos por un asiento en $1451{ }^{334}$, once en $1481{ }^{335}$ y en 1482 dos cahíces de trigo ${ }^{336}$. En la parte de los varones o "sinoga de los hombres" costó en 1487 un asiento que lindaba con la puerta de "man squierda", cien sueldos ${ }^{337}$ y otro,

${ }^{332} \mathrm{El}$ asiento al que me referiré en nota 334 , estaba «franco, libero e quito e seguro e sines de ningun cargo otro que por aquel siamos tenidos e obligados dar e pagar a la dita aljama ni a otri ninguno, etc.».

${ }^{333}$ En otro testamento que hizo Cinha Baylo en 1465, dejó sus casas y el asiento dicho a Abraham Amiello, a quien además hizo donación de todos sus bienes.

${ }^{334}$ El 22 de abril de dicho año, rabí Baruc Abencahal y su mujer Ester de Aranda vendieron al zapatero Jaco Gotina "un sitio, si quiere solar, do yo dita Ezter me ... acostunbro posar ..., que ys nuestro propio ... e en la çaga do los otros jodios ... se acostumbran posar a fazer horacion». El asiento estaba libre de cargas, sin que nada se tuviera que pagar por él a la aljama, y lindaba con el de la mujer de rabí Abraham, la difunta Duenya Gallur, y con el de la mujer del tejedor Acach Abenforna; por él se pagó la mencionada cantidad (L.A.APN., Martín de Marín, 1451, fols. 62v-63).

${ }^{335}$ El 18 de enero de 1481 Ceti Gallur, mujer de Saya Sumiel, «en virtut de una carta de gracia" que le otorgó a Soli de Levi, viuda de Jehuda Abenpesat, el 30 de julio de 1478 , le vendió "hun lugar, si quiere sitio de muller, sitiado en la sinoga de las mulleres jodias", que lindaba con el de Ceti Sumiel y con el de Ceti Gallur, mujer de Abraham Alfrangil. El precio, once sueldos, otorgó haberlo recibido (Z.APN., Antón de Abiego, 1494, fol. 83; donde se recoge el documento).

${ }^{336}$ El 23 de agosto de dicho año, el carnicero Juce Gotina, menor, vendió a Cer Gadax, viuda de Juce Albo, un lugar o sitio en la "sinoga de las mulleres", por dicha cantidad. Lindaba con el de Jamila Abenforna y con el de Merian, la mujer de Mosse Sumiel (dicho notario, 1482, fol. 85). El sitio de Merian o Marianica, como también aparece nombrada, pudo ser el que le dejó su tía Clara Almali, mujer de Jossuas Gallur, en el testamento que hizo en 1448.

${ }^{337}$ El 3 de abril de dicho año y por esa cantidad, la viuda Cer Gadax vendió a rabí Acach Cidiello un sitio en la "sinoga de los hombres", que lindaba con el de Salamon Levi y con la puerta de "man squierda»; tomó quinyan en poder de maestre Simuel Cavaller. La venta se hizo con "carta de gracia" de reventa cuando el comprador recibiera la cantidad entregada (dicho notario, 1487, fols. $34 v-35$ ). 
junto a la puerta de "man drecha", y "con una cadira de fusta y tabla pintada", dos florines de oro en $1490{ }^{338}$.

El sostenimiento de la sinagoga corría a cargo de todos los judíos de la villa, quienes, además de dar limosnas para los pobres de la comunidad ${ }^{339}$, entregaban aceite para sus lámparas ${ }^{340}$, hacían

${ }^{338}$ El 2 de noviembre de dicho año, el bilbilitano Juan de Valdivieso, como comisario o nuncio de los inquisidores Alonso Sánchez de Alarcón y maestre Martín García - según provisión dada el 30 de enero de 1489, en la Aljafería-, vendió a Hahim Sumiel, mayor y vecino de Épila, un lugar o sitio en la «sinoga de los hombres judios" de la villa, "junto con la puerta de man drecha de la dicha sinoga y man drecha de la dicha puerta". Lindaba con esta puerta y con lugar del mismo comprador; por él pagó Hahim dos florines de oro (dicho notario, 1490, fols. 117v118). En la sinagoga "clamada de Bicorholim, alias de Vesitar los Enfermos", de la ciudad de Zaragoza se pagaron doscientos sueldos, en 1450, por dos lugares contiguos, que lindaban con los del difunto don Bienvenist de la Caballería, con el de Zecri Abenbitas "e con la paret de la casa do stan las Atoras", cuando los vendió el converso Pedro Sánchez de Calatayud a Bonafos Abnarrabi. El mismo día de esta venta, 4 de marzo, Gonzalvo de la Caballería, hijo del citado Bienvenist, "en compensacion e satefaccion de muytos e diversos plazeres, honras e buenos merescimientos" que dicho Bonafos le había hecho, le donó "tres lugares de assentar o posar contiguos", sitos en la mencionada sinagoga, que habían pertenecido a su padre y que lindaban con lugares que fueron del difunto rabí Mosse Abenabez, con lugares del citado converso Pedro "e con la casa do stan las Atoras". Cuatro meses después el 10 de julio, el escudero y notario Juan de Veray, mayor, vendió a Soli Avenbruco "dos lugares de asentar contiguos, sitiados en la sinoga mayor de las jodias", que lindaban con el de Mira Abenaguaz, viuda de Simuel Algranat y con el de Oro Ceti, mujer de Salamon Matuniel; el precio que se pagó por ellos, cien sueldos, fue la mitad de lo que costaron los dos de la sinagoga de Bicorolim (Z.APN., Pedro Sánchez de Calatayud, 1450, fols. 1, 16-16v y 362).

339 Cinha Baylo mandó en su testamento, hecho en 1455, que sus ejecutores testamentarios pagaran "a la cedaqua de la aljama de los judios de Epila diez solidos" que le debía, "e por el descargo de mi anima ... sian pagados en satisfacion de aquellos, dotze»; en el que hizo en 1462 ordenó a su heredero universal Abraham Amiello que diera cuatro dineros "a la cedaqua", durante diez años. El mercader Nitzim Zunana mandó en su testamento, hecho en 1484, que "sean dados a pobres de almosna por amor de Dios y en tiempo de cinquo anyos cinquanta solidos. Es a saber en cada anyo ... la viespra de Quipur sean repartidos a los dichos pobres diez solidos y esto por mi anima y en remission de mis pecados y de las animas de aquellas personas a quien yo so en cargo de algun deudo".

${ }^{340}$ Clara Almali mandó en su testamento, hecho en 1448 que, después de su muerte, su marido Jossuas Gallur «sia tenido fazer cremar una lanpeda en la sinoga de Epila, de olio ... por tiempo de un anyo". Cinha Baylo en el testamento, hecho en 1462, quiso que, después de su muerte, Abraham Amiello, a quien hizo donación de todos sus bienes, tuviera que pagar cada año, durante diez, doce dineros: «quatro ... pora la cedaqua, quatro ... pora olio a la sinoga e los quatro dineros pora el rabi que sera en aquel tiempo". Muchos fueron también los conversos que, durante el siglo $\mathrm{XV}$, contribuyeron con limosnas y envíos de aceite para que alumbraran las lámparas de las sinagogas de sus lugares de residencia. Aunque la comunidad cristiana ayudaba al sostenimiento de las iglesias de la villa, hubo motivos especiales por los que el 
aportaciones pecuniarias para que se hiciera una mapa ${ }^{341}$ o una corona para la Tora ${ }^{342}$ y ayudaban cuando se recogían colectas para solventar determinadas necesidades; éstas y otras cantidades dejadas muchas veces en legados testamentarios, contribuían al mantenimiento de la sinagoga. Pero además, la sinagoga tenía capacidad jurídica para poseer en propiedad bienes inmuebles, como la iglesia ${ }^{343}$ y la mezquita, y fue dueña de unas casas, junto a un heredamiento

concejo cristiano se obligó a hacer determinadas concesiones a éstas. El 18 de marzo de 1422, reunido el concejo en la plaza, asignó «tres roas de olio" anuales: una, a Santa María, otra a San Cristobal de la iglesia de San Juan, y la tercera, a San Sebastián que "ys zerqua de Hurrea". Dicha asignación perpetua que recaía sobre la Dehesa de la villa, que "ys en el Plano", y sobre "el boalar" de ésta, se pagaría el día de Todos los Santos, para que la Virgen y los Santos fueran «atvocados ha nuestro senyor Dios que quiera reservar el dito pueblo de qualesquiere pedimias de mortalera, langosta, piedra, nievla e otras qualesquiere tenpestades" (L.A.APN., Remiro de Sádaba, 1422, fols. 29-29v).

${ }^{341}$ Otra de las obligaciones que Cinha Baylo impuso a su heredero universal Abraham Amiello, en el testamento que hizo en 1462, fue que comprara "una mapa o cubierta" para cubrir la Tora de la sinagoga, por valor de cien sueldos. También el zapatero Mosse Haddax, en su testamento hecho en 1482, dejó a la sinagoga "una mapa, si quiere vestimenta de Tora", que debería hacerse de "broquado sobre broquado" y por el equivalente a cuatrocientos sueldos.

342 Véase en el apartado anterior de este estudio, en la parte dedicada a don Lope Ximénez de Urrea, hijo del virrey, SEF LIII (1993) 290-292.

${ }^{343}$ Ya he aludido a la iglesia de la villa de Épila, de Santa María o de Santa María la Mayor, como también se la denominó, donde se instituyeron la mayor parte de las capellanías y aniversarios. Las conocidas como "eglesias de fuera" de la villa fueron las de San Juan y San Miguel, donde se instituyeron las capellanías de San Juan y San Miguel, y de San Nicolás y Santa María Madalena. No fue poco el poder del vicario, racioneros y capellanes o clérigos de la iglesia de Santa María, en la villa. Todos los clérigos de esta iglesia constituían el colegio de clérigos de Santa María y, en la primera mitad del siglo $\mathrm{XV}$, fueron dueños de fincas rústicas y urbanas; entre otras: unas casas y dos tiendas contiguas en la Plaza, otras casas en el barrio de Santa María, tres campos - dos de ellos contiguos- en el Cobdo, otros dos en los Yermos y siete campos más, sitos en el Vado de Mareca, en Pradiel de Gomar, en Albucea, en los Bairaces, en el Tellar, en Media Huerta y en San Miguel, términos de la villa; además de una viña en la Val de Lumpiaque. El colegio de clérigos de la iglesia de Santa María solía dar a treudo, perpetuo o temporal, todos estos inmuebles a particulares cristianos o moros; las casas del barrio de Santa María, según parece, las ocupaba el vicario de dicha iglesia. El importe de estos treudos no suponía para el colegio de clérigos grandes ganancias, unos cuarenta y seis sueldos y diez cahíces de trigo anuales; de ahí que, en ocasiones, el concejo cristiano de la villa tuviera que pagar el arreglo de la iglesia, como se ha visto. También el concejo -clérigos, infanzones y hombres de "signo servicio"- reunido en la plaza, "si quiere mercado", el 19 de noviembre de 1400, llegaba a un acuerdo por el cual "ordenamos e taxamos que el sagristan o sagristanes" que eran o fueran de la iglesia de la villa, que tocaran las campanas por algún difunto, "las mayores e chicas todas ensemble", tuvieran de salario dos sueldos, si sólo tocaban las mayores, cobrarían doce dineros y si única- 
de casas y corrales, en uno de los barrios de la villa ${ }^{344}$. Por lo que se refiere a bienes rústicos adquiridos en los términos de la villa por compra, donaciones piadosas o a través de legados testamentarios, cuyo arriendo y posterior cosecha podían contribuir a su sostenimiento, no consta documentalmente que la sinagoga los tuviera; una de las condiciones que se imponían al treudero judío, sobre todo si la propiedad pertenecía a una capellanía, era que no pudiera dejarla a "lampeda, spital, sinoga, ni vender aquella ...»" 345 .

Escenario de las ceremonias religiosas judías en la villa, la sinagoga estaba destinada a albergar otras actividades por ser el lugar donde la comunidad judía epilense trataba sus más graves problemas y adoptaba los más importantes acuerdos. En ella se resolvieron los asuntos generales y propios de la comunidad judía: constitución y juramento de los cargos públicos, aprobación de ordenaciones, recibimiento, lectura y aceptación de las órdenes de los señores, nombramiento de procuradores de la aljama, etc.; y en ella se acordaron los asuntos económicos: emisión y venta de censales, otorgamiento de recibo de comandas, repartimiento de impuestos, juramento sobre la usura según el fuero, etc. De todas estas actividades, además de las sociales y culturales, sólo se tiene constancia cuando se testifica-

mente las chicas, nueve dineros (L.A.APN., Martín de Talamanca, 1400, fols. 94v-95). El viernes 7 de abril de 1402, el vicario y un clérigo recibieron del procurador del concejo noventa sueldos de la "sagristania" de la villa, de ese año; y el siguiente 28 de julio dicho procurador pagó a dos clérigos setenta sueldos "et a otro cabo", cuarenta, del precio de dos cahíces de trigo, "por razon de la sagristania" de ese año (L.A.APN., Remiro de Sádaba, 1402, fols. 42 y 69). Años después, el 15 de marzo de 1426, el vicario de la iglesia de Santa María asignó al clérigo que era sacristán de dicha iglesia, sesenta sueldos "por el servicio e cosas que vos como sagristan fazeredes por mi» en ella; dicha cantidad la cobraría de cierta asignación a la que el vicario tenía derecho (L.A.APN., Martín de Talamanca, 1425, fol. 18). Los legados píos de los miembros de la comunidad cristiana solían hacerse, generalmente, mandando a los ejecutores testamentarios que distribuyeran determinada cantidad: "en huerfanas casar et en pobres bestir", en "dar a comer por amor de Dios ha V pobres de Dios", en "sendas sayas" para vestir a cinco pobres, etc., u ordenándoles que el producto de la venta de determinado inmueble se destinara a tales fines. Los legados píos a la iglesia de la villa solían ser de: "un anyal de oblada y candela", "una camisa de lino e misal", un caliz de plata y un marco, "huna lanpeda de plata ... de peso de siet honzas, para la qual lanpeda facer lexo huna taxa de plata ... e ... dos brandones de cera ... que coste cada brandon diez solidos", etc.

${ }^{344}$ Cuyo nombre no se especificó (L.A.APN., Martín de Talamanca, 1437, fol. 13v).

${ }^{345}$ Esa fue la condición que el clérigo y capellán Juan de Sangorrín impuso a Mosse Gallur, hijo de Salamon Gallur, el 5 de enero de 1425, cuando le entregó a treudo perpetuo, con fadiga y loísmo, la viña de su capellanía, sita en los Montarones (dicho notario, 1425, fol. 4). 
ron ante notarios cristianos o cuando ante éstos se aludió a las mismas; nada se sabe de los protocolos, actas y registros de los notarios judíos ante quienes se otorgaron los asuntos privativos de la aljama, que se conservarían en el archivo de la propia sinagoga. Hubo alguna ocasión en la que la aljama se congregó en las casas de los señores Ximénez de Urrea, como ocurrió en 1403 cuando reconoció una deuda contraída.

El edificio que albergó la sinagoga de los judíos siguió conservando el nombre después de la expulsión y salida de la villa de éstos, según ponen de manifiesto noticias documentales de los ocho últimos años del siglo XV. Cuando el 23 de mayo de 1493, Pablo de Aranda -antes rabí Acach Cidiello- recibió en comanda sesenta sueldos del labrador Miguel de Sariñena, respondió con sus casas sitas "a la puyada de la sinoga» ${ }^{346}$. Cuatro años después, el 25 de octubre de 1497, los escuderos de la casa del conde de Aranda, Juan de Aborera y Melchor de Gotor, vendieron "con fadiga, loysmo e comiso" al mercader converso Diego López -antes Juce Hazan, de Almonacid de la Sierra- ${ }^{347}$ «unas casas o si quiere granero" que tenían a treudo del conde don Miguel, con todas sus entradas, salidas, luces y vertientes de agua; el inmueble vendido estaba sito "a la partida de la sinoga que solia ser de los judios" y lindaba con dicha sinagoga y con callizo sin salida ${ }^{348}$. No adquirió el mercader converso Diego López "las casas o si quiere granero" por ningún motivo sentimental, porque al día siguiente las transfirió al citado escudero Melchor que, a continuación, volvió a venderlas al mercader zaragozano Francisco de Santa Cruz por la misma cantidad ${ }^{349}$. Muy cerca de la citada "partida" de la sinagoga, «en la

\footnotetext{
${ }^{346}$ Lindaban con las de Pedro García y con dos carreras públicas (L.A.APN., Martín Ramo, 1493, fol. 21v).

${ }^{347}$ Hermano de Abraham Hazan; luego aparecerá su nombre precedido del vocablo mosén y seguido su apellido de la palabra caballero.

348 Además de con las casas de Juan de Sarriá y con las de Estéfano de Carola. Dicho inmueble estaba gravado con ocho sueldos de treudo perpetuo anual que había que pagar a don Miguel o sus sucesores el día de Santa María de Agosto, según se especificó en el contrato hecho ante el notario y escudero Juan de Abiego - la fecha aparece en blanco-. Los ochenta sueldos del precio otorgaron los escuderos haberlos recibido; a su vez, el conde de Aranda que permitió la venta, recibió los ocho sueldos de la décima parte del precio, que le correspondía por razón del loísmo (dicho notario, 1497, fols. 178v-180; en fol. 181 se dice que las casas lindaban con las de María de Calatayud y con las de dicho Estéfano).

${ }^{349}$ Dicho notario y año, fols. $180 \mathrm{v}-182 \mathrm{v}$.
} 
carrera bulgarment de las ferrerias", tuvo en 1499 la capellanía instituida por el difunto don Miguel de Suñén, unas casas «que son siete portales contiguos", que lindaban con "caliço que no ha sallida, llamado la puyada de la sinoga" ${ }^{350}$, y otras, que lindaban con la carrera de las Herrerías y con "calliço de la puyada de la sinoga" ${ }^{351}$. Según estas noticias, al terminar el siglo XV el edificio de la sinagoga no había sido destinado a otro uso y en la villa seguían manteniéndose los nombres de "partida de la sinoga" y "caliço que no ha sallida, llamado la puyada de la sinoga" o "calliço de la puyada de la sinoga".

No consta documentalmente que hubiera en la villa centro alguno de instrucción pública — de haberlo estaría localizado seguramente en la sinagoga-, pero la aljama debió de preocuparse, en cierta medida, de la educación de los niños judíos, porque existió el cargo de «Rabi de los mozuelos», que desempeñó Astruch Avon en $1421{ }^{352}$, y el de «Rabi de los ninyos», que desempeñó Mosse Zunana en $1454{ }^{353}$. En ocasiones las personas que desempeñaron el cargo de rabí en la sinagoga fueron beneficiarias de mandas testamentarias ${ }^{354}$.

No se tiene constancia concreta de cuál fue el nivel cultural de los miembros de la comunidad hebrea de la villa, pero sería similar al que hubiera en otras aljamas del reino. Muchos judíos de las clases media y baja, al igual que los cristianos y moros, no sabrían

${ }^{350}$ Además de con las casas, corral y bodega de Luis de Rueda, y con carrera pública llamada de las Herrerías (dicho notario, 1499, fol. 147; en fol. 201, detrás de la palabra sinagoga, está escrito de los judíos y no dice que el callizo no tuviera salida). Dos de los portales contiguos de dichas casas los dio el capellán mosén Miguel de Macarín al tejedor Pedro de Vera a treudo perpetuo, con fadiga, loísmo y comiso. Lindaban con casas de Miguel López, con las de Alfonso de Oviedo, treuderas también a dicha capellanía, con "casas, si quiere corral", de Luis de Rueda y con carrera pública de las Herrerías (dicho notario y año, fol. 202).

${ }^{351}$ Además de, por dos partes, con casas treuderas a la misma capellanía y con las de Luis de Rueda. Las tuvo a treudo, con fadiga, loísmo y comiso, el sastre Martín de la Piera y su mujer Beatriz, quienes las vendieron al pelaire Miguel López (dicho notario y año, fol. 195).

352 Horbellido mandó en su testamento que «sian demandados a Estruch Avon, Rabi de los mozuelos, cinquo solidos que le preste».

${ }^{353}$ El 9 de septiembre de dicho año, Mosse actuó como procurador del escudero y mercader zaragozano Fortún de Roda (L.A.APN., Martín de Marín, 1454, fol. 82).

354 En su testamento de 1462 Cinha Baylo mandó a Abraham Amiello que entregara, durante diez años, cuatro dineros a quien desempeñara las funciones de rabí en la sinagoga. 
leer ni escribir; los más pudientes recibirían educación de profesores particulares ${ }^{355}$.

Las noticias documentales que a libros se refieren, como Aliça, Ciddur, Génesis o Libro Mayor, Hamas, Mahazxor, Meguilla, Petach Deberay, Raben Salamon, Sarassim, Teffila de Ros Asana y Tora Abay ${ }^{356}$, aparecen cuando los judíos los distribuyeron entre sus futuros herederos al otorgar testamento. La propiedad de determinados libros denota en algunos miembros de la comunidad interés por el estudio del hebreo.

\section{COFRADÍAS}

Al igual que en otras ciudades y villas del reino aragonés, la comunidad judía de Épila creó cofradías de carácter sociobenéfico y asistencial, que desempeñarían una función primordial en la práctica de la caridad entre los judíos ${ }^{357}$. No se conoce el número de éstas ni cuándo dieron licencia los señores Ximénez de Urrea para su creación, después de que los futuros cofrades elaboraran sus estatutos, pero consta documentalmente que, en 1421, ya eran varias las

355 Poco hay que añadir en lo que respecta a la comunidad cristiana. Para "los gastos en el studion de Zaragoza dejó Martina de Alfocea, en su testamento, a su hijo Guillén cien sueldos (L.A.APN., Remiro de Sádaba, 1400, fol. 122).

356 Citados por J. Cabezudo Astraín, "La judería de Epila", SeF XVII (1957) 104105, notas 6-8, que estudió el testamento del zapatero Mosse Adax. También el mercader Nitzim Zunana dejó a su hermano Salamon en el testamento que hizo en 1484, un Hamas en papel, un Cibdur y un Matzor.

${ }^{357}$ Por lo que se refiere a las cofradías religiosas de la comunidad cristiana, entre otras la de Santa María la Mayor, la de Santa María la Mayor de los Legos, la de Santa María de los Clérigos, la de la Misa de Santa María de los Clérigos y Santa María de los Abades, se "plegaban" en la iglesia de Santa María, la de los Clérigos, concretamente en la tribuna; "a las espaldas" de dicha iglesia se reunian los cofrades de la de las Virtudes. En la iglesia de San Juan se reunían las cofradías de San Juan, de San Nicolás y de Santa Lucía; y en la iglesia de San Miguel, la cofradía de su mismo nombre y, tal vez, la de Santa "Olalia». El ingreso en una cofradía se hacía a cambio de una cantidad en metálico o asignando un treudo sobre un inmueble del que pretendía pertenecer a ella. Los medios económicos con los que se sostenían las cofradías eran los treudos sobre sus propiedades rústicas y urbanas, los legados testamentarios de particulares y las asignaciones treuderas dichas sobre inmuebles de los cofrades; del patrimonio de las cofradías se ocupaban los mayordomos o procuradores de éstas. 
cofradías judías en la villa ${ }^{358}$. Dichas cofradías, cuyos bienes patrimoniales no parece que estuvieran siempre libres de impuestos, se financiaban: por una parte, del capital para obras piadosas que se obtenía de los impuestos recaudados para cubrir los gastos de la aljama; por otra, de las cuotas que anualmente entregarían los asociados o cofrades por recibir sus servicios; y por una tercera, de la generosidad de algunos miembros de la comunidad a través de donaciones y legados testamentarios. No hay constancia documental de que los arrendadores de las sisas de la carne y el vino quedaran obligados a entregar determinados artículos a cofradías en algunas fiestas judías, según lo acordado en la firma de los capítulos de arrendación con la aljama.

Las cofradías judías, como se ha dicho, tuvieron capacidad jurídica para poseer bienes inmuebles al igual que las cristianas. De la administración y del reparto de las cuotas de las limosnas y legados píos que la cofradía recibía se encargaban sus adelantados o mayordomos ${ }^{359}$ y los propios cofrades. En ocasiones, la administración de algunos de estos bienes se dejó en manos de un particular que recibió las casas y corral de la cofradía a treudo, a cambio de determinadas prestaciones, entre otras: pagar "la peyta" correspondiente, hacer determinadas obras, acoger a los judíos pobres lo mejor que pudiera, recibir una vez al año la visita de los adelantados $\mathrm{y}$, en caso de conversión, "relexar et desenparar" dichos bienes a los cofrades, pues en el compromiso se hico constar: "no dar ni relexar» el inmueble a cristiano.

Algunas de las cofradías judías, como «la confraria de la aljama" ${ }^{360}$, estarían vinculadas con el organismo para beneficencia de la aljama y adscritas a la sinagoga directamente; otras, pudieron estar relacionadas con la aljama y adscritas también a la sinagoga, en un

${ }^{358}$ En el testamento que hizo la judía Horbellido, en 1421, dejó veinte sueldos a cada una de "las cofrarias de los judios de Epila».

${ }^{359} \mathrm{La}$ judía Bellita que hizo testamento en 1466 «slio exsecutores e cabeçaleros a mi anima a los adelantados ... e a los mayordomos de la ... cofraria de la aljama".

${ }^{360} \mathrm{La}$ citada Bellita en dicho testamento dejó a sus hijos y parientes cinco sueldos por los bienes muebles y cinco por los inmuebles - legítima foral-, y, como sus herederas universales, "todos los otros bienes ... lexo de gracia special a la aljama de los judios de la juderia de la dita villa de Epila e a la confraria de la aljama ... que aquellos todos ... partan por yguales partes. Et aquesto por tanto que ... me han subvenido, si quiere socorrido por muitas y diversas en mis necessidades mas que fillos ni parientes ningunos mios". 
principio, y pasar luego a ser entidades autónomas o nacer como tales.

Otra de las cofradías judías, la de Bicorolim, consta que estuvo establecida en la villa, al menos, desde el primer cuarto del siglo XV y como, al parecer, necesitó para realizar su función un centro hospitalario propio, se destinaron las casas y corral de dicha cofradía para este uso.

El 2 de octubre de 1417, Simuel Calloxa, Salamon Bivach y Simuel Estallo, adelantados, y Salamon Fichel, don Mosse Gallur, hijo de Simuel Gallur, Jaco Gotina, Jaco Zuri, Juce de Omar y Sento Eli, en sus propios nombres y en nombre «e en voz de todos los cofraderes de la cofraria de Visitar Enfermos", dieron a treudo perpetuo, "con comiso", a Acach de Leredi unas casas y corral de dicha cofradía ${ }^{361}$. Los diez sueldos del treudo debía pagarlos Acach el día de San Miguel, en septiembre, o un mes después y las condiciones que se le impusieron fueron las siguientes: a) pagar la "peyta" que le correspondiera a los dos inmuebles; b) hacer en el corral en los próximos dos años, a partir de la firma del contrato, "hun palacio bien e suficientment a conoximiento de los adelantados de la dita cofraria»; si no lo hacía, caería "en comiso" como si no hubiera pagado el treudo; c) «recullir los pobres de Dios que sian judios, a los quales les fagaz el millor recullement que podrez"; d) no vender, empeñar ni de cualquier otro modo alienar a persona alguna, excepto a sus hijos o herederos, las casas y corral; si lo hacía, caería "en comiso»; e) si se hacía cristiano, debería de "relexar et desenparar las ditas casas e corral a los ditos cofrades"; en ese caso caerían "en comiso" como si no hubiera pagado el treudo; f) no podía "dar[los] ni relexar[los] a christiano ninguno»; y g) permitir que los adelantados actuales o los que lo fueran en el futuro visitaran cada año las casas y corral. Los adelantados se comprometieron a mantener a Acach como treudero y obligaron sus bienes a cumplirlo; a continuación y para mantener y cumplir lo pactado, los adelantados "prendieron quinyan en poder" de rabí Saya. Acach

${ }^{361}$ Lindaban con las casas de los clérigos, con callizo por donde tenían su entrada y salida y con casas que fueron de Pedro de Azafar. Recuérdese que en 1405 las casas de este clérigo, bachiller en decretos y racionero de la villa, lindaban con la sinagoga. Cuando en dicho año el clérigo Pedro de Azafar hizo testamento, mandó que se diera a los clérigos de Épila «la pitança, ys a saber, una canal de carnero, dos cantaros de bino e II sueldos de pan", cuando él muriera (L.A.APN., Martín de Talamanca, 1405, fol. 49v). 
recibió los inmuebles a treudo perpetuo de diez sueldos anuales, que pagaría en el plazo acordado y bajo las condiciones dichas, obligó sus bienes y también "prendio quinyan en poder» del mismo rabí ${ }^{362}$.

De una tercera "cofraria de la aljama de Epila, clamada Hoce Cedacot", se tiene noticia desde la segunda mitad del siglo XV, concretamente desde 1455, cuando la judía Cinha Baylo ordenó en su testamento que sus ejecutores testamentarios compraran, con el dinero procedente de la venta de parte de los bienes muebles de su casa, "dos livros" para dicha cofradía "e no para otra ninguna", que deberían entregar a los adelantados de ésta. Dicha "cofraria de la aljama de los judios de la juderia" de la villa, fue dueña de unas casas en el barrio del Burgo ${ }^{363}$, que la misma Cinha le legó, "a honor de nuestro senyor Dios e a salvacion de mi anima e por satisfacion de mis pecados", con la condición ineludible de que los cofrades distribuyeran todos los años diez sueldos, cinco la "vispra de la festa Hyon Quipur» y los otros cinco "la viespra de Pascua clamada Peça» ${ }^{364}$.

Por tanto, fueron al menos tres las cofradías judías de la villa cuyo nombre se conoce; otros legados testamentarios sólo aludieron a la "hebra o confraria de los confradres judios de la villa», sin especificar más, refiriéndose, tal vez, a la cofradía de la aljama ${ }^{365}$.

\section{HosPITAL}

En el mismo barrio de la Sinagoga, y posiblemente lindando con el edificio que la albergaba, tuvieron los judíos un centro de beneficencia y asilo donde se atendía al necesitado, el hospital para los pobres de la comunidad. No consta si su fundación partió de la aljama, de un particular o de una cofradía, ni si en alguna ocasión se requirió para mantenerlo la colaboración de todos; podían ingresar

${ }^{362}$ L.A.APN., Remiro de Sádaba, 1417, fols. 35-36v.

${ }^{363}$ Lindaban con las del señor don Lope Ximénez de Urrea -que fueron de los monjes de Veruela y tenía a treudo Pascuala Fort-, con las de los hijos de Abraham Amiello y con carrera pública.

${ }^{364}$ Recuérdese lo dicho en notas 3 y 323.

${ }^{365}$ Cinha Baylo en el testamento que hizo en 1462, quiso que se dieran cincuenta sueldos "pora la hebra o confraria de los confradres judios" de la villa. 
en él no sólo los judíos epilenses, sino también peregrinos y extranjeros de su misma ley religiosa ${ }^{366}$.

¿Fueron las casas y corral de la cofradía de Bicorolim el primer edificio que los judíos de la villa utilizaron como hospital o existió otro en Épila? La documentación examinada alude al hospital judío u hospital de los pobres de la judería, propiamente dicho, desde el año 1421, pero seis años después, en 1427, unas casas del hospital de los judíos lindaban con las de Acach de Leredi -que desde 1417 tuvo a treudo perpetuo las casas y corral de dicha cofradía ${ }^{367}-\mathrm{y}$ de su mujer Bellita de Mora ${ }^{368}$. En 1482 el hospital de los pobres de la judería lindaba con las casas de Ceti de Arrueti - viuda de Juce Abencida-, sitas "en el barrio de la Sinoga" ${ }^{369}$, que lo hacían, a su vez, con las de Mosse Sumiel, con corral de Juan Sánchez de Sarriá y con callizo por donde tenían su entrada y salida ${ }^{370}$.

Con capacidad jurídica para poseer patrimonio propio, el hospital se sostendría con lo que obtuviera de sus bienes inmuebles al igual que la sinagoga, con limosnas, donaciones pías y legados testamentarios. Nada se sabe sobre la distribución de sus dependencias, capacidad y dotación de lechos, pero éstos se incrementarían, en 1421 , con "huna camenya de ropa, do yo duermo en casa mia», que le dejó la judía Horbellido "por Dios e por mi anima» y, posteriormente, con

${ }^{366}$ Son muchas las noticias que se refieren al "espital de los pobres" de la comunidad cristiana de la villa que recibía, en ocasiones, la tercera parte de las multas en que incurrían quienes incumplían determinados ordenamientos del concejo. Entre los varios inmuebles de su patrimonio se encontraban algunas tiendas en el barrio de la Plaza. El 5 de mayo de 1451, el procurador del hospital Juan Vidal reconoció haber treudado una de las tiendas nuevas del hospital, sitas en la plaza, a Duenya Gallur, por veinte sueldos anuales y perpetuos (L.A.APN., Martín de Marín, 1451, fol. 66).

${ }^{367}$ Recuérdese que lindaban con casas del racionero Pedro de Azafar y que éstas, en 1405 , lindaban con la sinagoga.

${ }^{368}$ Que, a su vez, lo hacían con corral de la capellanía de Juan de Sangorrín (L.A.APN., Martín de Talamanca, 1427, fol. 18).

369 El 23 de agosto de 1482, Ceti vendió sus casas, libres de cargas, al sastre Jaco Gallur por doscientos cincuenta sueldos, pero con la condición de que las habitaciones bajas tenían que ser comunes para los dos. Aceptada la condición, Jaco se obligó a que, si en el plazo de cuatro años Ceti le pagaba dicha cantidad o se volvía a casar, se las revendería. El siguiente 1 de septiembre Ceti volvía a ser dueña de sus casas al haber pagado a Jaco los doscientos cincuenta sueldos (Z.APN., Antón de Abiego, 1482 , fols. $83 v-84 v$ y $88 v-89$ ).

${ }^{370}$ Recuérdese el requerimiento que hizo Juan Sánchez de Sarriá, merino en 1461, porque el agua que escurría del "terrado" de la sinagoga, estaba dañando su casa. 
«un leyto de ropa en el qual ... aya un almadrach travesero, dos linçuelos e litera, de la millor ropa que sera trobada en mi casa apres de mis dias",

que "por servicio de nuestro senyor Dios" le legó Cinha Baylo ${ }^{371}$. Los bienes del hospital de los judíos pobres los administrarían los adelantados o el hospitalero o, como en el caso del hospital de los cristianos pobres, el procurador o el "recebidor de las rendas" de éste ${ }^{372}$.

\section{MIQWEH}

Un único documento hace referencia al baño que los judíos de Épila construirían en "hun patio, si quiere solar, sito al puent clamado de la Nodriza" ${ }^{373}$, término de la villa, que lindaba

"de part de suso con la cequia de la dicha villa, con carrera publica a la una part e al suelo con campo que fue de Adam de Ortuvia et de la otra part con rasa que salle de la dicha cequia para regar el dicho campo".

El solar lo donó el señor don Lope Ximénez de Urrea, hijo del virrey, el 1 de agosto de 1476, a los adelantados y cofrades de la "cofraria de judios ... vulgarment clamada de Oçe Çedacot", para que "podades fazer hun banyo e casa" e hicieran de aquél "a todas vuestras propias voluntades como de bienes et cosa vuestra propia». La razón de la donación la basó el señor en «algunos servicios ... que nos haveys fechos e Dios quisiendo fareys" ${ }^{374} \mathrm{y}$ al especificar en ella que lo utilizaran como si se tratara de bienes propios, cabe pensar que el solar quedó libre de cargas y que las cuotas que se pagaran por su uso serían para dicha cofradía y servirían para su mantenimiento, calentamiento, limpieza, etc.; todo ello dando por

${ }^{371}$ En los testamentos que hicieron en 1421 y 1455, respectivamente.

372 El 10 de noviembre de 1400 , el clérigo Domingo López de Pomar, “como recebidor que so de las rendas pertenecientes al spital» de la villa, recibió ...

373 J. Cabezudo Astraín, "La judería de Épila», 104 y 109, se refirió brevemente a este baño, pero unió el instrumento público de la donación.

374 Z.APN., Antón de Abiego, 1476, fols. 66v-67; a ello aludí en el primer apartado de este estudio en las noticias referentes a dicho año. 
supuesto que se llegara a construir y que los judíos no tuvieran otro baño, porque si se hizo y hubo otro, el baño de dicha cofradía pudo ser privativo de sus cofrades.

\section{Cementerio}

Las únicas noticias documentales encontradas que hacen referencia a fosar o cementerio judío, proceden de los testamentos que los miembros de la comunidad hebrea otorgaron ante notarios cristianos de la villa ${ }^{375}$. Llama la atención la preferencia de algunos judíos residentes en Épila por ser enterrados fuera de la villa. Las mujeres eligieron para ser sepultadas el fosar de los judíos del lugar de Rueda: como fue el caso de Horbellido en 1421, al pedir que se hiciera allí "su sepultura, si quiere enterrorio", «bien e honrradament segunt que a mi conviene»; de Clara Almali, mujer de Jossuas Gallur, que "slio mi sepultura" en dicho fosar, en 1448; de Cinha Baylo en 1455, que dijo que su "cuerpo sia enterrado" allí, "do a mis exsecutores sera bien visto"; y de Bellita en 1466, que pidió que su "cuerpo ... sia soterrado" en dicho fosar, "con aquella solepnidat que la aljama e honbres buenos de los judios de Epila havran por bien fazerme». En el fosar de los judíos de Zaragoza quiso que se le enterrara el mercader Nitzim Zunana en 1484, "al costado do jaze mi madre, la qual sepultura quiero que me sea fecha bien et honrradament segunt a mi conviene», que su cuerpo fuera "soterrado con

${ }^{375}$ En cuanto al cementerio cristiano, si se exceptúan algunos escuderos, cuyos antepasados estaban enterrados en la iglesia de El Pilar, de Zaragoza, que ordenaron en sus testamentos se les sepultara allí, la mayoría de los cristianos de la villa quisieron ser enterrados en el cementerio de la iglesia de Santa María de Épila o cementerio de la iglesia, como también se le llamaba, especificando algunos, además, "alli do ys el enteritorio de mi linage" o de algún familiar, y asignando determinadas cantidades para que se hiciera su sepultura. Para ser enterrado dentro de la iglesia de Santa María, se necesitaba un permiso especial que, en ocasiones, se obtuvo dotando o asignando a ésta y a sus clérigos o capellanes un aniversario sobre determinado inmueble: "por razon que an collido soterrar ... dentro, en el coro". Entre las familias que tenían este privilegio se encontraban: Juana Sánchez de Sancha Aznar, mujer del escudero Pedro Garcés de Rueda, cuya familia podía enterrarse "devant del altar de Santa Maria, en el coro"; los García de Rueda, que podían hacerlo een el tomulo ..., a la entrada de la puerta de la iglesia", a mano izquierda; los Urrea, "en el tomulo" de su familia; los Dolz, "cerca del cruxifixo de los Spedas"; los Arbués, "en la capiella de Sant Martin, alli do ys sepellido don Pero de Epila d'Arbues, caballero"; etc. 
taut y lucillo", y que se pusiera sobre ella una piedra de treinta sueldos de precio. De todos los testamentos estudiados de judíos de la villa, sólo el zapatero Mosse Haddax pidió en 1482 que su cuerpo se enterrara «en el fosar de los jodios» de Épila, "alli et en aquel lugar do a mi suegro don Saya Sumiel sera visto". ¿Es posible que hasta este último año la comunidad hebrea no tuviera cementerio propio? Nada puede decirse con base documental al respecto ${ }^{376}$, pero resulta extraño que hasta 1482 no aparezca la más mínima alusión al cementerio judío de Épila en la abundante documentación notarial examinada; lo que fuera de él, después de la expulsión, se ignora.

[Continuará]

${ }^{376}$ Recuérdese lo dicho al final de la nota 7. 